WellBeing International

WBI Studies Repository

$12-1992$

\title{
Sow Preference for Farrowing-Crate Width
}

\author{
P. A. Phillips \\ Agriculture Canada \\ David Fraser \\ Agriculture Canada, dfraser@mail.ubc.ca \\ B. K. Thompson \\ Agriculture Canada
}

Follow this and additional works at: https://www.wellbeingintlstudiesrepository.org/houcfani

Part of the Agribusiness Commons, Animal Studies Commons, and the Operations and Supply Chain Management Commons

\section{Recommended Citation}

Phillips, P. A., Fraser, D., \& Thompson, B. K. (1992). Sow preference for farrowing-crate width. Canadian Journal of Animal Science, 72(4), 745-750.

This material is brought to you for free and open access by WellBeing International. It has been accepted for inclusion by an authorized administrator of the WBI Studies Repository. For more information, please contact wbisr-info@wellbeingintl.org.

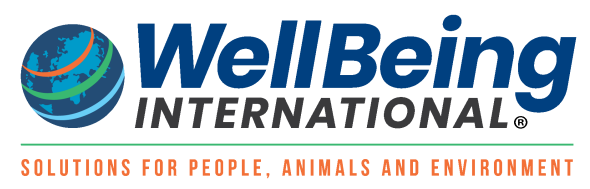




\title{
Sow Preference for Farrowing-Crate Width
}

\author{
P.A. Phillips, David Fraser, and B.K. Thompson \\ Agriculture Canada
}

\section{KEYWORDS}

sow, farrowing crate, equipment design, preference testing, animal welfare

\begin{abstract}
A preference-testing apparatus was designed to provide sows with continuous access to three farrowing crates of different widths. The crates radiated from a central hub area sufficiently large for sows to enter or leave any crate freely. In exp. 1, nine sows were offered crates of 450-, 600- and 750-mm width at standing height. In exp. 2, 12 sows were offered widths of 450,750 and $1200 \mathrm{~mm}$, the largest being of sufficient width for the sow to turn around. Video recording was used to determine sow position from $3 \mathrm{~d}$ before to $6 \mathrm{~d}$ after farrowing. In exp. 1, sows showed a preference for the widest crate of 750 $\mathrm{mm}$ during and after farrowing $(P<0.05)$ but not before. In exp. 2, the $1200-\mathrm{mm}$ width was preferred before, during and after farrowing $(P<0.005)$ over the widths that were too narrow to permit turning. Sufficient space for turning appears to be preferred by sows around the time of farrowing.
\end{abstract}

Sows in semi-natural habitats typically select farrowing sites with certain features. Farrowing sites are usually away from other sows and sheltered in trees or brush, and the sows normally scoop out a dishshaped nest area, which they surround with branches and other available material (Stolba and WoodGush 1984; Jensen et al. 1987; Jensen 1989).

Efforts have been made to characterize farrowing-site preference in controlled preference experiments. Sows have chosen to build nests and farrow on soils (loam or sand) rather than on concrete (Hutson and Haskell 1990; Arey et al. 1991). Sows also seem to prefer a nest site with some degree of visual enclosure (Hunt and Petchey 1987, 1989; Phillips et al. 1991). The motivation to construct a nest is strong in sows and is not reduced by providing an adequate pre-formed nest site (Arey et al. 1991). However, the importance to the sow of having access to nest-building material such as straw requires more study: using operant tests, Hutson (1988) found sows were not prepared to work for a straw reward at farrowing, but Arey et al. (1989) showed that easily available straw will be well used by sows at that time. Thus, even in artificial indoor environments, sows not previously exposed to outdoor habitat display many of the preferences seen in semi-natural environments.

From an animal welfare viewpoint, the restriction of movement imposed by farrowing crates is the most controversial aspect of farrowing-crate design. Many crates impede the sow's normal standing and lying movements, while some fail to accommodate even the basic body dimensions of the sow (Baxter and Schwaller 1983). Restriction of the sow is credited with reducing piglet deaths (English et al. 1977), but some evidence suggests that this benefit of close confinement of the sow has been overestimated 
(Fraser 1990). Critics have also suggested that the restriction imposed by farrowing crates causes undue stress on the sow (Baxter and Petherick 1980), interferes with the farrowing process (Schouten 1991), and prevents the sow from carrying out the natural pattern of movements that protect piglets when she lies down (Clough 1984). Furthermore, some crate designs interfere with piglet access to the udder (Fraser and Thompson 1986). Nonetheless, there has been little study of the space allowance actually preferred by sows, and the one relevant preference experiment concluded that sows prefer narrow farrowing sites (Baxter 1991). This study examines sow preferences for different farrowing-crate widths.

Fig. 1. Layout of the preference-testing apparatus, showing the crate widths used in exp. 2.

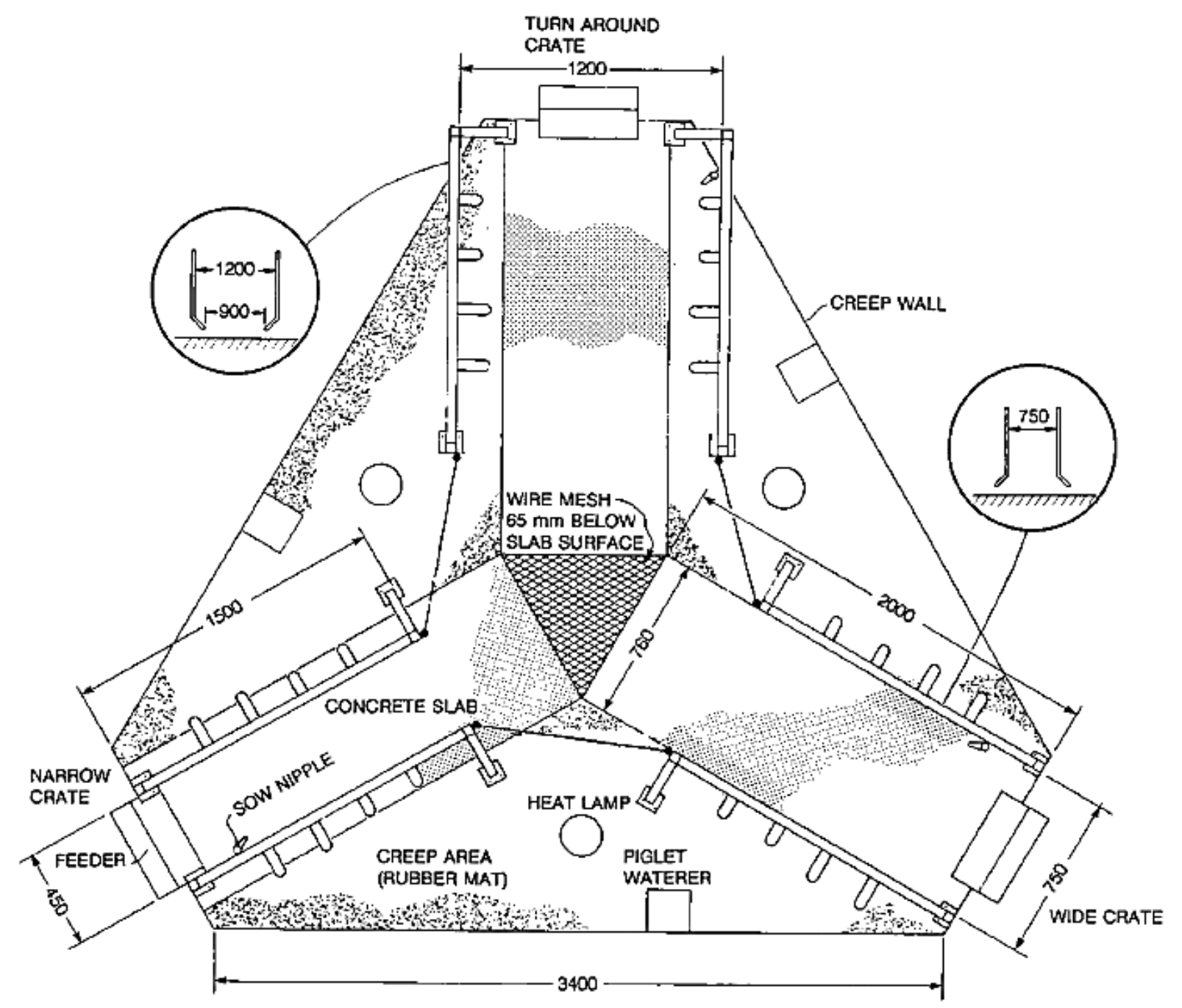

MATERIALS AND METHODS

\section{Test Apparatus}

A test apparatus was designed to offer individual sows free access to three farrowing crates that could be altered to test the animals' preference for various design features. The three crates, each $1.5 \mathrm{~m}$ long, radiated from a central hub area sufficiently large to allow sows to exit from each crate and move freely 
into another (Fig. 1). The crates were made with tubular horizontal rails on both sides and tubular prongs attached to the lowest rail, angling down and slightly outward from the sow. The side assemblies could be adjusted to form a crate of any desired width. Concrete-slab flooring was used under all three crates. The floor of the hub area was expanded metal, recessed $5 \mathrm{~cm}$ below the concrete to make the floor uncomfortable and discourage lying in this area. Each crate was equipped with a feeder forming the front end of the crate. The apparatus was mounted on a platform $300 \mathrm{~mm}$ above the floor and was located in a temperature-controlled room $\left(24-28^{\circ} \mathrm{C}\right)$ at the Centre for Food and Animal Research's minimum-disease facility in Ottawa. Further dimensions and construction details are available in Phillips et al. 1991.

\section{Treatments and Experimental Design}

In exp. 1, three crate widths (450-, 600- and 750-mm inside width at the sow's standing height; prongs pointing away from the sow at an angle of $30^{\circ}$ from vertical) were offered to nine sows. The 450-mm width was typical of a relatively narrow commercially available crate, while $750 \mathrm{~mm}$ exceeded crate widths generally available in North America but was still too narrow for the sow to turn around. To protect against possible position effects in the room, each treatment (i.e., each crate width) was offered an equal number of times in each segment of the preference-testing apparatus as determined by three Latin squares.

In exp. 2, the range of crate-width options was expanded to include one crate sufficiently wide for a sow to turn around, as well as two of the previous options (450 and $750 \mathrm{~mm}$ ). A diagram of the apparatus (Fig. 1) shows this particular arrangement. The turn-around option was patterned after a crate design proposed by Fraser et al. (1988) and consisted of sides spaced $1200 \mathrm{~mm}$ apart at the sow's standing height with prongs sloping inward on the bottom of both sides so that the sow's resting area was restricted to a width of $900 \mathrm{~mm}$. This resting area is similar to that available in the $750-\mathrm{mm}$-width crate with prongs sloping outward. Twelve sows were used, with each crate width presented an equal number of times in each position as determined by four Latin squares.

\section{Animals and Procedures}

Second- and third-parity Yorkshire and Yorkshire $\times$ Landrace sows were placed in the apparatus about 5 $\mathrm{d}$ before the farrowing due date and were removed $7 \mathrm{~d}$ after farrowing. The sows were previously accustomed to farrowing in crates $0.6 \mathrm{~m}$ wide and $2 \mathrm{~m}$ long. Their daily ration was divided equally among the three feeders and was delivered to the feeders in randomized order to ensure that sows visited all crates each day. The testing apparatus was thoroughly washed after each sow, and sows were used only once.

The sows' use of the crates was monitored by time-lapse video recording with a single overhead camera and wide-angle lens. One frame was recorded every 3 min throughout the experiment. The video tapes were analyzed to give records of the sow's crate choice and posture in each frame, with posture scored as either active (standing or sitting) or lying. Results were expressed in three 72-h periods, each comprising 1440 observations: the $72-\mathrm{h}$ period before farrowing $(-72 \mathrm{~h}$ to $0 \mathrm{~h}=$ period 1$)$ ending when newborn piglets were first observed, and two consecutive 72-h periods during and after farrowing $(0 \mathrm{~h}$ to $+72 \mathrm{~h}=$ period 2 ; and $+72 \mathrm{~h}$ to $+144 \mathrm{~h}=$ period 3 ), the first beginning when newborn piglets were first seen. Previous experience with this apparatus indicates that sow location during a 3-d period after farrowing has commenced corresponds closely to sow location during the actual parturition. No records of piglet behavior were gathered.

\section{Statistical Analysis}

The analysis was based on the sows' selection of crates when lying, as this behavior generally accounts for over $85 \%$ of the sow's time. Preliminary analysis showed little evidence of any effects of position in the 
room. Because of difficulties with the distribution of percentages, statistical comparisons for each period were based on the nonparametric Friedman's test (Siegel 1956), which ignores position effects.

Fig. 2. Mean ( \pm SEM) percent time spent resting in each of the farrowing crates, expressed as a percentage of total time spent resting, for the three time periods during exp. 1 and exp. 2. Crates are identified by their width $(450,600,750,1200)$ in millimetres.

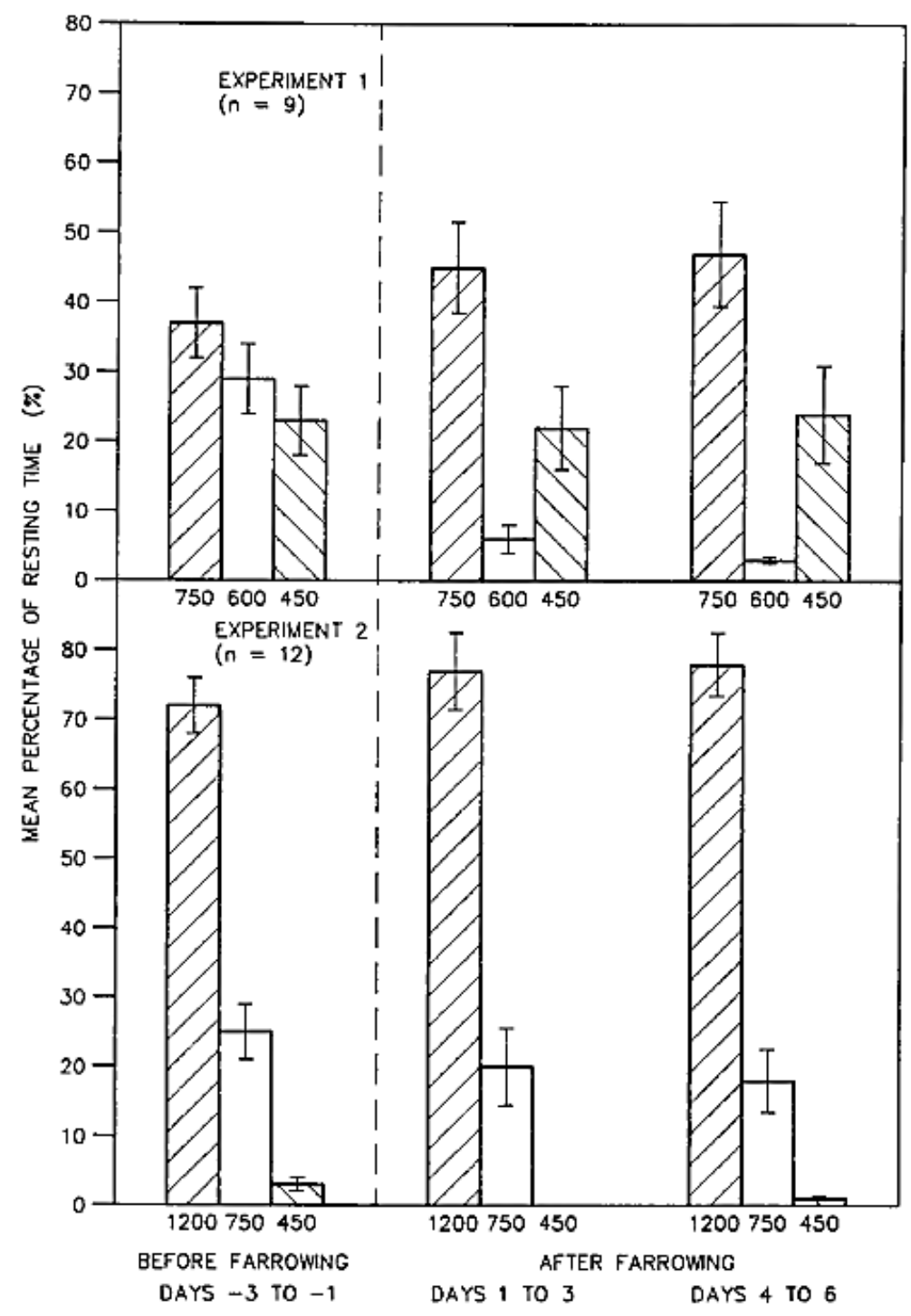

\section{RESULTS}

\section{Experiment 1}

Sows showed no strong preference for crate width before farrowing $(P=0.67)$, but did so after farrowing $(P<0.05)$ (Fig. 2). Sows preferred the widest crate $(750 \mathrm{~mm})$ after farrowing and spent about $46 \%$ of their total lying time in that crate. The second most preferred option was not the 600 or $450 \mathrm{~mm}$ width, but the hub or central area of the pen, which was used during $28 \%$ of lying time. The use of the central hub area explains why the averages in Fig. 2 do not add up to 100\%. On the day of farrowing ( $0 \mathrm{~h}$ to $+24 \mathrm{~h}$ ) and during the hours of birth, five sows spent most of their time in the widest crate, two in the medium, and one in the narrow; the other sow preferred the hub area. These findings, in particular the relatively high 
use of the more spacious hub area, suggested that an even wider crate option might elicit a clearer preference by sows.

\section{Experiment 2}

Sows showed clear preferences both before and after farrowing $(P<0.001)$, with the widest $(1200 \mathrm{~mm})$ turnaround crate preferred and the $450-\mathrm{mm}$ crate virtually ignored (Fig. 2). The number of sows preferring the $1200-\mathrm{mm}$ crate (nine) was significantly greater $(P<0.02)$ than even those preferring the $750-\mathrm{mm}$ crate (three). Before farrowing 9 of the 12 sows showed a clear preference for the turn-around crate and spent an average of $84 \%$ of their resting time in this crate; after farrowing this rose to $92 \%$ for these sows. One sow preferred the $750-\mathrm{mm}$ crate before farrowing and the turn-around crate during periods 2 and 3. The remaining two sows preferred the $750-\mathrm{mm}$ crate throughout. In all cases, sow location during parturition was consistent with the position preferred during the 72-h period beginning at the start of farrowing. Time spent lying in the central hub area was much lower in this experiment (2\%) than in experiment 1.

\section{DISCUSSION}

When given a choice of farrowing-crate widths, the sows favored the widest option provided in both experiments. In exp. 1, where the widest crate $(750 \mathrm{~mm})$ was not sufficient for the sow to turn, this option was preferred over the others, but it attracted only about half of the sows' lying time, and sows spent about one-quarter of their lying time in the central hub area of the apparatus (where turning was possible), even though the floor of this area was designed to minimize comfort. In exp. 2, where the widest crate did permit sows to turn around, this option attracted a large majority of the sows' lying time, and use of the central hub area was negligible. Thus, while wider crates seemed to be generally preferred, a width sufficient to permit turning appeared to make the preference more decisive. Sows rarely changed location once farrowing had commenced, particularly in exp. 2 , where a clearly preferred option was offered.

Superficially, these findings appear to contradict those of Baxter (1991), who concluded "that sows have a significant preference for small farrowing sites." In Baxter's experiment, three potential farrowing sites (550, 950 and $1350 \mathrm{~mm}$ wide) were centrally located in a large room such that the sows could walk directly through each farrowing site and turn around in a spacious area at either end. Under these conditions, the narrowest enclosure was the most often selected (by 21 of 48 sows). However, this finding may apply only to cases - such as the application targetted in Baxter's work - where the sows are free to walk through the farrowing site. Furthermore, while the narrow site was chosen more often than the others, a majority of sows farrowed in less confining parts of the environment. Finally, because Baxter's experiment used solid partitions for the farrowing sites, the sows using the narrow site may have been selecting for greater visual enclosure rather than for a physically confining space. As the contrast between Baxter's results and ours illustrates, conclusions from environmental preference tests need to be drawn with care because methodological details can have unexpected impacts on the results (Fraser et al. 1992). Further tests using different procedures would be useful to test the generality of the findings.

The turn-around option in exp. 2 was based on a crate design (Fraser et al. 1988) in which the sow has adequate room to perform her normal postural changes, but the sides of the crate slope inward toward the floor to help the sow to lie down in a controlled manner and to restrict the sow's lying area to a width similar to that offered by much more restrictive crates. This crate, as well as other turnaround designs (e.g., Collins et al. 1987; McGlone and Blecha 1987), appears, based on preliminary tests, to be similar to conventional crates in piglet protection, cost, and building-space requirements. In addition, the results of 
this study indicate that a turn-around farrowing-crate design should positively affect the welfare of the sow.

\section{ACKNOWLEDGMENTS}

The authors wish to thank D. Alves, J.-M. Leclerc, E. Bérubé, B. Pawluczuk and R. Pella for their valuable assistance in this study.

\section{REFERENCES}

Arey, D. S., Petchey, A. M. and Fowler, V. R. 1989. Farrowing site preference by sows. Anim. Prod. 48: 643. (Abstr.)

Arey, D. S., Petchey, A. M, and Fowler, Y. R. 1991. The preparturient behaviour of sows in enriched pens and the effect of pre-formed nests. Appl. Anim. Behav. Sci. 31: 61-68.

Baxter, M. R. 1991. The "freedom" farrowing system. Fm. Bldg. Prog. 104: 9-15.

Baxter, M. R. and Petherick, J. C. 1980. The effect of restraint on parturition in the sow. Proc. Int. Pig Vet. Soc., 1980 Congress, Copenhagen, Denmark. p. 84.

Baxter, M. R. and Schwaller, C. E. 1983. Space requirements for sows in confinement. Pages 276-311 In S. H. Baxter, M. R. Baxter and J. A. D. MacCormack, eds. Animal housing and welfare. Martinus Nrjhoff, The Hague, The Netherlands.

Clough, C. E. 1984. An evaluation of the farrowing crate. Fm. Bldg. Prog. 76: 21-26.

Collins, E. R. Jr., Kornegay, E. T. and Bonnette, E. D. 1987. The effects of two confinement systems on the performance of nursing sows and their litters. Appl. Anim. Behav. Sci. 17: 51-59.

English, P. R., Smith, W. J. and Maclean, A. 1977. The sow -- improving her efficiency. Farming Press Ltd., Ipswich, U.K.

Fraser, D. 1990. Behavioural perspectives on piglet survival. J. Reprod. Fertil. Suppl. 40: 355-370.

Fraser, D. and Thompson, B. K. 1986. Variation in piglet weights: relationship to suckling behavior, parity number and farrowing crate design. Can. J. Anim. Sci. 66: 31-46.

Fraser, D., Phillips, P. A. and Thompson, B. K. 1988. Initial test of a farrowing crate with inward-sloping sides. Livest. Prod. Sci. 20: 249-256.

Fraser, D., Phillips, P. A. and Thompson, B. K. 1992, Environmental preference testing to assess the wellbeing of animals -- an evolving paradigm. J. Agric. Environ. Ethics. (In press.)

Hunt, K. and Petchey, A. M. 1987. A study of environmental preferences of sows around farrowing. Fm. Bldg. Prog. 89: 11-14.

Hunt, K. and Petchey, A. M. 1989. Degree of enclosure preferred by sows around farrowing. Anim. Prod. 48: 643. (Abstr.) 
Hutson, G. D. 1988. Do sows need straw for nest-building? Aust. J. Exp. Agr. 28: 187-194.

Hutson, G. D. and Haskell, M. J. 1990. The behaviour of farrowing sows with free and operant access to an earth floor. Appl. Anim. Behav. Sci. 26: 363-372.

Jensen, P. 1989. Nest site choice and nest-building of free-ranging domestic pigs due to farrow. Appl. Anim. Behav. Sci. 22: 13-27.

Jensen, P., Florén, K. and Hobroh, B. 1987. Peri-parturient changes in behaviour in free-ranging domestic pigs. Appl. Anim. Behav. Sci. 17: 69-76.

McGlone, J. J. and Blecha, F. 1987. An examination of behavioral, immunological, and productive traits in four management systems for sows and piglets. Appl. Anim. Behav. Sci. 18: 269-286.

Peo, E. R., Jr. 1960. Round stall for farrowing. Nebr. Exp. Stn. Q. 7: 9.

Phillips, P. A., Fraser, D. and Thompson, B. K. 1991. Preference by sows for a partially enclosed farrowing crate. Appl. Anim. Behav. Sci. 32: 35-43.

Schouten, W. G. P. 1991. Effects of rearing on subsequent performance in pigs. Pig News Info. 12: 245247.

Siegel, S. 1956. Nonparametric statistics for the behavioral sciences. McGraw-Hill. London, U. K.

Stolba, A. and Wood-Gush, D. G. M. 1984. The identification of behavioural key features and their incorporation into a housing design for pigs. Ann. Rech. Vét. 15: 287-298. 